\title{
Knowledge management awareness in a research and development facility: Investigating employee perceptions
}

\begin{tabular}{|c|c|}
\hline \multicolumn{2}{|c|}{$\begin{array}{l}\text { Authors: } \\
\text { Andrea Potgieter } \\
\text { Thami Dube }^{1} \\
\text { Chris Rensleigh }^{1}\end{array}$} \\
\hline \multicolumn{2}{|c|}{$\begin{array}{l}{ }^{1} \text { Department of } \\
\text { Information and Knowledge } \\
\text { Management, University of } \\
\text { Johannesburg, South Africa }\end{array}$} \\
\hline \multicolumn{2}{|c|}{$\begin{array}{l}{ }^{2} \text { Centre for Information and } \\
\text { Knowledge Management, } \\
\text { University of Johannesburg, } \\
\text { South Africa }\end{array}$} \\
\hline \multicolumn{2}{|c|}{$\begin{array}{l}\text { Correspondence to: } \\
\text { Andrea Potgieter }\end{array}$} \\
\hline \multicolumn{2}{|c|}{$\begin{array}{l}\text { Email: } \\
\text { apotgieter@uj.ac.za }\end{array}$} \\
\hline \multicolumn{2}{|c|}{$\begin{array}{l}\text { Postal address: } \\
\text { PO Box 524, Auckland Park } \\
\text { 2006, South Africa }\end{array}$} \\
\hline \multicolumn{2}{|c|}{$\begin{array}{l}\text { Received: } 30 \text { July } 2013 \\
\text { Accepted: } 11 \text { Nov. } 2013 \\
\text { Published: } 04 \text { Dec. } 2013\end{array}$} \\
\hline \multicolumn{2}{|c|}{$\begin{array}{l}\text { How to cite this article: } \\
\text { Potgieter, A., Dube, T. } \\
\text { \& Rensleigh, C., 2013, } \\
\text { 'Knowledge management } \\
\text { awareness in a research } \\
\text { and development facility: } \\
\text { Investigating employee } \\
\text { perceptions', SA Journal of } \\
\text { Information Management } \\
\text { 15(2), Art. \#592, } 6 \text { pages. } \\
\text { http://dx.doi.org/10.4102/ } \\
\text { sajim.v15i2.592 }\end{array}$} \\
\hline \multicolumn{2}{|c|}{$\begin{array}{l}\text { Copyright: } \\
\text { ( } 2013 \text {. The Authors. } \\
\text { Licensee: AOSIS } \\
\text { OpenJournals. This work } \\
\text { is licensed under the } \\
\text { Creative Commons } \\
\text { Attribution License. }\end{array}$} \\
\hline \multicolumn{2}{|l|}{ Read online: } \\
\hline 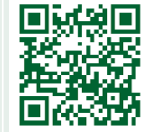 & $\begin{array}{l}\text { Scan this QR } \\
\text { code with your } \\
\text { smart phone or } \\
\text { mobile device } \\
\text { to read online. }\end{array}$ \\
\hline
\end{tabular}

Background: Research and development (R\&D) facilities are dependent on knowledge to develop new and improve existing technologies. R\&D employees' perceptions of the use and management of knowledge are important as these individuals are the source of the innovation needed to generate and develop new processes and services.

Objectives: This study aimed to understand Sasol R\&D employees' perceptions of knowledge management (KM). The study also assessed the attitude of Sasol R\&D management towards KM.

Method: The target population for this research included different levels of seniority and education in Sasol R\&D. A questionnaire was distributed to a sample of 150 employees in R\&D and 50 more who work closely with R\&D in support functions.

Results: It was found that the importance of KM is understood by Sasol R\&D employees and management. It was established that Sasol R\&D management regard KM as important, but that their commitment to KM initiatives is not necessarily evident for employees. A concern highlighted by the study was that employees were not aware of the duties of the identified KM champions within their facility.

Conclusion: It was suggested that Sasol R\&D employees should be made aware of the duties of KM champions. It was also established that Sasol R\&D management needs to be more visible in their support of KM initiatives. Recommendations based on the findings of the study can assist Sasol R\&D, and other facilities attempting to implement a KM strategy, to gain insight into the perceptions of employees and the role management needs to play in the facilitation of this process.

\section{Introduction}

Research and development (R\&D) facilities are dependent on knowledge to develop new and improve existing technologies. R\&D employees' attitude towards the use and management of knowledge is important as these individuals are the source of the innovation needed to generate and develop new processes and services for an organisation. R\&D is critical for companies to remain competitive in a modern knowledge and innovation-based economy.

Sasol, a global petrochemical group, was formed in 1950 after the South African government wanted to reduce the country's dependency on foreign oil supply. To achieve this goal, Sasol used Fischer-Tropsch (F-T) technology, which used the gasification of coal to produce hydrocarbon products that included synthetic fuels. Today, the organisation supplies approximately $35 \%$ of South Africa's fuel needs. In 1955 the management of Sasol commissioned a laboratory and a testing station with 70 technicians and scientists. In 1957 a formal R\&D facility was formed and was named Sasol Technology. Sasol Technology currently employs individuals qualified mostly in various fields of engineering and science; more than 500 postgraduate employees in these fields are employed by the facility.

Knowledge management (KM) strategies result from knowledge workers' awareness of trends in the current business environment, and their responses to those trends (Ndlela \& Du Toit 2001:156). The primary objective of this study was to establish Sasol R\&D employees' perceptions of KM within the facility.

R\&D facilities are commonly used to enhance an organisation's products and services, to ensure a the organisation gains and maintains a competitive edge (Sambamurthy \& Subramani 2005). R\&D employees are therefore referred to as 'knowledge workers', as they are usually highly educated (Van der Spek \& Kingma 2000), implying that their value as employees is tacit. These individuals' level of education, as well as their experience, is important in sustaining innovation, since the 
primary objective of R\&D facilities is to utilise knowledge to develop and improve products and services.

This study aimed to understand Sasol R\&D employees' perceptions of $\mathrm{KM}$ in the organisation. The study also assessed the attitude of Sasol R\&D management towards $\mathrm{KM}$, since the formulation of a KM strategy depends on the ability of management to change the corporate culture into one that creates opportunities for tacit knowledge to be made explicit (Ndlela \& Du Toit 2001:156).

The recommendations of this study incorporate the views and opinions of the employees to establish what actions are necessary for the KM strategy that has been adopted to be successful. These recommendations, and key results of the study, were presented at an international conference of KM practitioners and academics in 2012 (Potgieter, Dube \& Rensleigh 2012). By assessing whether employees identify and take ownership of the strategy that has been adopted, the facility can identify the needs of its employees and ensure that the maximum level of benefit is gained from this adopted strategy. Recommendations from the results can also assist Sasol R\&D management in ensuring that the KM strategy that has been adopted is effective and can deliver positive results for the organisation.

\section{Knowledge management in Sasol research and development}

Bishop et al. (2008:17) mention that the need organisations have to make better use of their knowledge resources has commanded the adoption of effective KM initiatives as a business solution. Despite the complex nature of knowledge, it is closely related to knowing how to 'get things done' for the benefit of an organisation (Guo \& Sheffield 2008). Universally, and specifically in a R\&D environment, organisational knowledge is an intangible intellectual asset that: 'plays an important role in the success of any enterprise' (Ndlela \& Du Toit 2001:161). This is true in general, but specifically in a technology-driven business environment like Sasol.

In a knowledge-intensive environment such as $R \& D$, for an organisation to remain competitive, it has to have a knowledge advantage (Mrinalini \& Nath 2008). Furthermore, knowing how to 'get things done' in an R\&D facility is critical because of the nature of the business. Therefore, $\mathrm{KM}$ and a subsequent strategy for managing knowledge as a resource can be considered an integral part of the success of a R\&D facility. Sasol R\&D's criteria for their current KM strategy were based on and benchmarked against internal (within Sasol) and external organisations' best practices (De Wet-Viljoen 2006).

The chosen criteria for the current KM strategy were that it must:

- be better than practices before it

- be proven

- be applicable across Sasol

- be affordable, implementable and sustainable

- add 'obvious and desired' values.
These criteria were a combination of internal and external organisational experiences and recommendations from academic publications. The benchmarking exercise was chosen because it made it easy to compare organisational criteria and simplified the process of making an informed decision. Based on these criteria, and the: 'KM pyramid of excellence' (De Wet-Viljoen 2006), the current KM strategy for Sasol's R\&D was developed.

The KM pyramid of excellence currently used by Sasol ensures that all aspects of KM implementation are addressed and that these aspects contribute to the growth of the organisation in the long term. As mentioned, for a KM strategy to be successful within an organisation, there has to be a culture that will promote knowledge sharing; the KM pyramid of excellence emphasises the importance of knowledge transfer to the improvement of knowledge levels within Sasol. After improving knowledge levels, the next step in the KM pyramid of excellence is to create and promote a learning organisation that will lead to the development of competency levels of the employees. According to this reasoning, if the competency of employees is continuously improved, employees may be more motivated to contribute to the knowledge of the organisation.

The ability of an organisation to utilise knowledge to get things done and maintain a competitive advantage is more important for organisations with: 'global ambitions' (Massa \& Testa 2009:129). One of the strategies of expanding organisations like Sasol is the formation of joint ventures with local and foreign organisations to enter new markets. The skills and knowledge in the appropriate selection of partners and the management of the alliance can make an important positive contribution to the success of the collaboration (Draulans, De Man \& Volberda 2003:155). The successful formation and management of the joint ventures requires that organisations contribute different areas of expertise, both technical and business related. Efficient KM in an $R \& D$ facility can give such an organisation a competitive advantage during the formation of these joint ventures.

For an organisation to realise its innovative capacity, it should be able to continuously: 'identify new ways of doing business, develop new technologies and products and enter new markets in new organisational forms' (Teng 2007:119). This is critical in Sasol R\&D since innovative ways of doing things and producing new and improving existing products has to be cost effective. The other main objective of a KM strategy is to facilitate effective and efficient knowledge sharing amongst the organisation's employees (Shin 2004:179). If employees share knowledge and experiences, the new and old ideas and procedures can be combined to result in new and improved production processes and products.

Therefore, the feelings and perceptions of employees towards the adopted KM strategy are important in ensuring the success of the initiative and knowledge sharing in the organisation. The perceptions that employees have of the adopted KM strategy can motivate or discourage employees 
to be creative and innovative. This aspect of $\mathrm{KM}$ is especially important in an R\&D environment.

Many organisations implement KM strategies on the assumption that competitiveness and efficiency will increase (Schultze \& Leidner 2002:219). Researchers and practitioners alike agree that structuring and enlargement of the knowledge base can improve its contribution to the effectiveness of the R\&D processes (Lee, Kim \& Koh 2009:3662). The availability of knowledge to employees, as was mentioned earlier, can enable employees to be innovative and ensure that the organisation achieves the best from its employees. The current KM strategy adopted within Sasol aims to ensure that the significance of KM is communicated from the lowlevel employees of the organisation to top management.

\section{Literature review}

\section{Research and development facilities: In general and at Sasol}

Research and development facilities function as knowledge bases in their organisations, providing a competitive advantage for innovative firms (Jackson, Hitt \& Denisi 2003). Successful organisations have the ability to create, disseminate and utilise knowledge efficiently and effectively (Sanghani 2008:7). It can therefore be argued that organisations that have R\&D facilities perceive the development of their knowledge base as vitally important in developing and sustaining their competitive advantage. The efficient utilisation of knowledge generated by a R\&D facility enables an organisation to develop new and innovative products and processes. This makes R\&D the core activity in ensuring an organisation's sustainability of innovation and thus its competitive advantage (Huang 2009).

The main objective of R\&D is to develop systems that can enhance productivity and performance within an organisation (Kumaraswamy et al. 2006:681). Organisations, especially organisations with $R \& D$ facilities, have to stay abreast of advances in relevant technologies in order to maintain a market leader position. To ensure a leading position, R\&D facilities employ specialists, who are employed because of their specialist knowledge in their respective fields, in order to give organisations a competitive advantage (Van der Spek \& Kingma 2000:21). R\&D facilities require personnel who also have strong academic backgrounds and who are experts in their respective fields of study. Organisations generally employ postgraduates in their R\&D facilities, as these individuals have a combination of academic and practical knowledge of the subject being researched (Van der Spek \& Kingma 2000:21).

As a strategy to attract and retain these skilled individuals, Sasol encourages and finances its employees to complete master's and doctoral degrees. However, the employee must research topics that are relevant to Sasol's business objectives and which will add value to the organisation's knowledge about the subject. This strategy not only ensures that the employee becomes an expert in the chosen subject; it also ensures that the organisation can maintain a competitive edge in that specific field of research.
As mentioned, Sasol Technology (Sasol's R\&D facility) was formed in 1957 and has been pivotal in the establishment of Sasol as the world leader in F-T technology, allowing the organisation to maintain a first-mover advantage and be the spearhead in the chosen market. Sasol has achieved this market leader status through the continuous improvement of current processes and technologies to reduce operational costs, and through collaboration with other industry-related parties. The R\&D facility at Sasol has significantly contributed to the continuous improvement of their technologies and processes, as is evident from the various awards and accolades Sasol has received for the contributions it has made in the technology development and engineering field.

\section{Defining knowledge management}

According to Foss, Husted and Michailova (2010:456), it is widely accepted that the management of knowledge has become: 'a critical issue for competitive dynamics, international strategy, the building of resources, the boundaries of firms, and many other issues'. In the last decade, knowledge has emerged as a resource that can contribute to an organisation's sustainable competitive advantage (Lopes 2008:7). The existing business environment is fast changing and requires organisations to exploit the knowledge and skills they possess in an efficient way to ensure their survival. Knowledge has become an important factor in creating and maintaining a competitive advantage in this dynamic and turbulent business environment (Davis, Subrahmanian \& Westerberg 2005:109).

Knowledge as a resource is scarce and valuable only when it is used (Forcadell \& Guadamillas 2002:163). Knowledge should therefore be considered as a strategically important resource (Grant 1996, as quoted in Forcadell \& Guadamillas 2002:163). Knowledge management can, in effect, be defined as the management of a highly valuable organisational resource, explaining why: 'making the most from their knowledge has always been organizations' Holy Grail' (Sultan 2013:160).

According to Du Plessis (2008), KM should be viewed as a process for managing an enterprise's intellectual assets, as it is a:

planned, structured approach to manage the creation, sharing, harvesting and leveraging of knowledge as an organisational asset, to enhance a company's ability, speed and effectiveness in delivering products or services for the benefit of clients, in line with its business strategy. (p. 286)

Dana, Korot and Tovstiga (2005:10) define KM as the management of the integration of organisational information and ideas to generate value for the organisation by facilitating the sharing of knowledge and, through this, promoting continuous organisational learning. Van Bereven (2002) and Robbins (2003) define KM as the process that can be utilised to collect and distribute the collective wisdom within an organisation for the relevant people, to make critical decisions, linking KM strategy to business strategy (LópezNicolás \& Meroño-Cerdán 2011:503). KM is also described as a process that can promote and facilitate the sharing of 
knowledge within an organisation (Singh 2008:5) to assist organisations that want to maintain or achieve a competitive advantage in ensuring that the KM strategies implemented are managed efficiently (Ndlela \& Du Toit 2001:155).

The culture within an organisation has to promote knowledge sharing and transfer to ensure a successful KM strategy (Ndlela \& Du Toit 2001:160); the increasing relevance of knowledge as a critical organisational resource has encouraged managers to pay greater attention to their organisations' KM strategies (Choi, Poon \& Davis 2008:235). Managers are realising the value of $\mathrm{KM}$, since it exposes employees to alternative practices and problem-solving techniques and it can be used to combine 'depth and richness' of experience (Jayawarna and Holt 2009:775).

A successful KM strategy can produce the necessary organisational information required to get the job done better and more efficiently than before (Call 2005:20) and allows improvement of an organisation's learning capability (Forcadell \& Guadamillas 2002:162). Finally, KM is strategically important as it can be used as a managerial tool to promote knowledge creation and sharing, which are essential in promoting the innovation process within an organisation (Constantinescu 2009:7) as organisational knowledge plays an important role in the innovation process (López-Nicolás \& Merono-Cerdán 2011:502).

\section{Research methodology}

A quantitative research methodology was chosen to measure employees' perceptions of KM within Sasol. A survey was distributed to employees of varying years of experience, education levels, races and genders. For the purpose of this research, non-probability convenience sampling was chosen to test if the employees' perceptions of KM are affected by their age, level of education and level of seniority. Convenience sampling was selected to ensure that the sample of the target population represented Sasol R\&D employees' perceptions of KM. The target population for this research was 200 employees with varying levels of seniority and education within Sasol R\&D, which is based in Sasolburg, South Africa.

The sampling approach aimed to represent all selected categories of employees and to establish whether there are any links that can contribute to shaping the employees' perceptions of KM within Sasol R\&D. The questionnaire was distributed to over 150 employees in Sasol R\&D and others who work closely with R\&D in support functions, but are still part of the Sasol Technology organisation. The questionnaire was web deployed via SurveyMonkey ${ }^{\circledR}$, an online survey deployment tool. A web-based survey was selected as the targeted population had access to the internet and were computer literate enough to complete the questionnaire without assistance. The completed questionnaires were then captured by STATCON (the Statistical Consultation Services at the University of Johannesburg) for processing and conversion into numerical format for statistical analysis.

\section{Analysis and interpretation of the empirical findings}

\section{The sample population}

The target population for this research included 200 employees with different levels of seniority and education in Sasol R\&D, based in Sasolburg. The sample was chosen to represent all categories of employees and to establish whether there are any criteria that contribute to shaping employees' perceptions of KM within Sasol R\&D. The questionnaire was distributed in 2011, to a sample of 150 employees in Sasol R\&D and 50 more who work closely with R\&D in support functions and are still part of the Sasol Technology organisation.

Table 1 presents some detail of the 54 employees who responded; three employees preferred not to disclose their gender. The total response rate was $36 \%$.

\section{Understanding knowledge management in Sasol research and development}

Since the objective of this study was to establish Sasol R\&D employees' perceptions of the current KM strategy within Sasol R\&D, it was important to establish whether the respondents were familiar with the concept of KM and whether they were familiar with the current KM strategy. Of the respondents, $80 \%$ indicated that they were familiar with the concept of KM; only 15\% indicated no knowledge of $\mathrm{KM}$ or uncertainty relating to $\mathrm{KM}$. Most of the respondents $(67 \%)$ indicated that they have knowledge of the current KM strategy within Sasol R\&D.

Ndlela and Du Toit (2001:164) highlight the assigning of a knowledge leader to any KM initiative as very important. The knowledge leader usually plays the role of a 'knowledge champion' with support from top management. This role: 'should not be made a separate portfolio but the knowledge champion should encourage development of knowledge management qualities in individuals throughout the enterprise'. Jones, Herschel and Moesel (2003:59) mention that knowledge champions: 'work with innovators and opinion leaders to institutionalise and codify new knowledge' in such a way that adds value and renders the knowledge useful and logical within the organisation.

In Sasol R\&D, only $23 \%$ of the respondents indicated that they understood the duty of the KM champions (the individuals acting as KM catalysts) to a moderate and large extent. The majority of respondents $(60 \%)$ indicated that they

TABLE 1: A demographical distribution of respondents based on race and gender.

\begin{tabular}{llll}
\hline Gender & $\begin{array}{l}\text { Number of } \\
\text { respondents }\end{array}$ & $\begin{array}{l}\text { \% participation of } \\
\text { total sample }\end{array}$ & $\begin{array}{l}\text { \% participation per } \\
\text { gender }\end{array}$ \\
\hline Black women & 6 & 11.1 & 24.0 \\
Black men & 5 & 9.3 & 18.5 \\
White women & 15 & 27.8 & 60.0 \\
White men & 17 & 31.5 & 63.0 \\
Indian women & 4 & 7.4 & 16.0 \\
Indian men & 4 & 7.4 & 14.8 \\
Other & 3 & 5.6 & - \\
\hline Total & $\mathbf{5 4}$ & $\mathbf{1 0 0}$ & - \\
\hline
\end{tabular}


understood the duties of KM champions to a small or to no extent. This is concerning, since employees take their lead from KM champions and thus a clear understanding of what these KM champions can deliver is crucial.

When respondents were asked whether they perceived KM as important in Sasol R\&D, 61\% indicated they did perceive KM as important in this facility; however, $52 \%$ indicated that they were not familiar with Sasol R\&D's KM strategy. This confirms that, even though Sasol R\&D employees recognised that $\mathrm{KM}$ was an important asset to Sasol $\mathrm{R} \& \mathrm{D}$, a large number of employees were not familiar with the strategy to ensure the effective management of knowledge.

\section{The perceived value of knowledge management}

Respondents were asked whether they thought KM can give an organisation a competitive advantage; $72 \%$ of respondents agreed that $\mathrm{KM}$ can give an organisation a competitive advantage. Employees also saw the value of KM to individual employees: $24 \%$ and $46 \%$ of respondents indicated that KM can improve the contribution of individual employees to a 'large extent' and 'moderate extent', respectively. The positive perceptions illustrated by these results bode well for Sasol R\&D, as KM should be a voluntary activity: 'the value proposition should be sold to them so that they can see the benefit of knowledge management' (Du Plessis 2008:289).

Furthermore, according to $44 \%$ of respondents, KM has improved the innovation of Sasol R\&D employees and $35 \%$ of respondents indicated that the current KM strategy has improved knowledge transfer amongst Sasol R\&D employees in general. It should be noted that the time frame of employment for respondents ranged from one year, to 23 years. This indicates general perceptions by Sasol R\&D employees that KM in fact adds value to the organisation.

The R\&D facility of an innovative organisation embodies the knowledge-based capability of the organisation that wants to maintain and sustain competitive advantage (Jackson, Hitt \& Denisi 2003). An innovative organisation is continuously learning and improving the employees' capabilities and skills to ensure that the competitive advantage of the organisation is sustained. Most of the respondents (80\%) agreed that $\mathrm{KM}$ is the foundation of a learning organisation whilst $72 \%$ indicated that KM can help the organisation's competitive advantage. The majority of respondents (70\%) indicated that KM can improve knowledge sharing within Sasol R\&D. The overall perception that is reflected by employees' responses is that KM is a valuable strategy to have within Sasol R\&D because it can improve the employees output and, therefore, the organisations' competitive advantage and profitability.

\section{Management and the knowledge management strategy}

In order for a KM initiative, such as developing and implementing a KM strategy, to be successful, top-level support is crucial; without this level of support, a KM initiative will never work (Bishop et al. 2008:23). Du Plessis
(2008:288) highlights the importance of the involvement of organisational management in $\mathrm{KM}$ initiatives by stating that management support of KM initiatives: 'creates trust and respect amongst other members of staff, which makes it easier for staff to participate'. The active support of KM initiative by management also creates: 'a feeling of integrity in the organisation and recognition for the knowledge they share' (Du Plessis, 2008:288).

It was evident from the results that a significant number of respondents $(41 \%)$ were of the opinion that management took KM initiatives within Sasol R\&D seriously. However, $41 \%$ of the respondents were of the opinion that management promotes a KM culture to a 'small' or to 'no extent'; only $24 \%$ of the respondents indicated that management promoted a $\mathrm{KM}$ culture to 'a moderate extent'. This is concerning, since the organisational culture sets the tone of knowledge sharing and ultimately KM within the organisation.

Almost half $(48 \%)$ of the respondents, also indicated that they are of the opinion that the Sasol R\&D KM strategy does not reach employees. This illustrates the disconnect that employees feel towards the current KM strategy, indicating that they do not feel part of the initiative. Further reiterating this conclusion, more than half of the respondents (56\%) were of the opinion that management only involves employees in Sasol R\&D KM initiatives to a 'small extent' or to 'no extent'. Based on these findings, it can be argued that the concern is not necessarily that Sasol R\&D management does not regard KM as important, but that their commitment to these initiatives are not relayed to the employees and therefore are not significantly evident in the organisational culture that Sasol R\&D management promotes.

\section{Conclusion}

It was established that $R \& D$ facilities are dependent on knowledge to develop systems that can enhance productivity and performance within an organisation and to develop new and improve existing technologies. It was also established that the perceptions that R\&D employees have regarding the use and management of knowledge is important since KM should be a voluntary activity. The importance of knowledge within $R \& D$ facilities and the perceptions that $R \& D$ employees have of how this knowledge is managed is therefore clear.

This study specifically aimed to establish the perceptions that Sasol R\&D employees have of KM in their organisation. The study also assessed the manner in which Sasol R\&D management is perceived to interact with knowledge, mainly through the implementation of a KM strategy. In general, it was discovered that Sasol R\&D employees have a positive perceptions of the value that KM can add to their organisation, both on a strategic and an individual level.

A concern highlighted by the study was that Sasol R\&D employees were not aware of the duties of the identified KM champions within their facility, which could potentially 
lead to knowledge gaps or a lack of knowledge sharing. As mentioned, this finding is concerning, since employees take their lead from KM champions and thus a clear understanding of what these KM champions can deliver is crucial.

As far as Sasol R\&D management's perceived contribution to creating a KM culture is concerned, it was established that Sasol R\&D management regard KM as important, but that their commitment to the KM initiatives is not necessarily evident to employees. This lack of apparent support is the reason for the lack of a knowledge sharing organisational culture, which Sasol R\&D management essentially promotes.

In conclusion, it can be noted that the importance of $\mathrm{KM}$ is understood by Sasol R\&D employees and management alike. Sasol R\&D employees need to be made aware of the duties of KM champions in order to take advantage of the services relating to KM that these individuals can offer. Finally, Sasol $R \& D$ management needs to be more visible in its support of the facility's KM initiatives, specifically all processes relating to the KM strategy. Management should also actively involve Sasol R\&D employees in the development of a KM strategy and subsequently the revision of such a strategy after implementation. Once this has been achieved, the benefits drawn from the KM strategy can aid Sasol R\&D in enhancing productivity and performance within the facility and it can support employees in developing innovative new technologies whilst continuously improving those that already exist.

\section{Acknowledgements Competing interests}

The authors declare that they have no financial or personal relationship(s) that may have inappropriately influenced them in writing this article.

\section{Authors' contributions}

T.D. (University of Johannesburg) conducted this study at Sasol towards the completion of his dissertation for the MCom in Business Management degree. C.R. (University of Johannesburg) and A.P. (University of Johannesburg) acted as supervisor and co-supervisor respectively.

\section{References}

Bishop, J., Bouchlaghem, D., Glass, J. \& Matsumoto, I., 2008, 'Ensuring the effectiveness of a knowledge management initiative', Journal of Knowledge Management 12(4), 16-29. http://dx.doi.org/10.1108/13673270810884228

Call, D., 2005, 'Knowledge management - not rocket science', Journal of Knowledge Management 9(2), 19-30. http://dx.doi.org/10.1108/13673270510590191

Choi, B., Poon, S.K. \& Davis, J.G., 2008, 'Effects of knowledge management strategy on organizational performance: A complementarity theory-based approach', Omega The International Journal of Management Science 36(4), 235-251. http://dx.doi. org/10.1016/j.omega.2006.12.003

Constantinescu, M., 2009, 'Knowledge management: Focus on innovation and labour productivity in a knowledge-based economy', The Icfai University Journal of Knowledge Management VII(1), 7-33.

Dana, L., Korot, L. \& Tovstiga, G., 2005, 'A cross-national comparison of knowledge management practices', International Journal of Manpower 26(1), 10-22. http:// dx.doi.org/10.1108/01437720510587244

Davis, J., Subrahmanian, E. \& Westerberg, A.W., 2005, "The "global" and "local" in knowledge management', Journal of Knowledge Management 9(1), 101-112. http:// dx.doi.org/10.1108/13673270510582992
De Wet-Viljoen, S., 2006, Internal benchmarking best practices identified, Sasol Technology, Johannesburg.

Draulans, J., De Man, A.P. \& Volberda, H.W., 2003, 'Building alliance capability management techniques for superior alliance performance', Long Range Planning 36(2), 155-166. http://dx.doi.org/10.1016/S0024-6301(02)00173-5

Du Plessis, M., 2008, 'What bars organisations from managing knowledge successfully?', International Journal of Information Management 28(4), 285-292. http://dx.doi. org/10.1016/j.ijinfomgt.2008.02.006

Forcadell, F.J. \& Guadamillas, F., 2002, 'A case study on the implementation of a knowledge management strategy oriented to innovation', Knowledge and Process Management 9(3), 162-171. http://dx.doi.org/10.1002/kpm.143

Foss, N.J., Husted, K. \& Michailova, S., 2010, 'Governing knowledge sharing in organizations: Levels of analysis, governance mechanisms, and research directions', Journal of Management Studies 47(3), 455-482. http://dx.doi.org/10.1111/j.14676486.2009.00870.x

Guo, Z. \& Sheffield, J., 2008, 'A paradigmatic and methodological examination of knowledge management research: 2000 to 2004', Decision Support Systems 44(3), 673-688. http://dx.doi.org/10.1016/j.dss.2007.09.006

Huang, C., 2009, 'Knowledge sharing and group cohesiveness on performance: An empirical study of technology R\&D teams in Taiwan', Technovation 29(11), 768-797. http://dx.doi.org/10.1016/j.technovation.2009.04.003

Jackson, S.E., Hitt. M.A. \& Denisi. A.S., 2003, Managing knowledge for sustained competitive advantage: Designing strategies for effective human resources management, HB Printing, USA.

Jayawarna, D. \& Holt, R., 2009, 'Knowledge and quality management: An R\&D perspective, Technovation 29(11), 775-785. http://dx.doi.org/10.1016/j.technovation. 2009.04.004

Jones, N.B., Herschel, R.T. \& Moesel, D.D., 2003, 'Using "knowledge champions" to facilitate knowledge management', Journal of Knowledge Management $7(1)$ 49-63. http://dx.doi.org/10.1108/13673270310463617

Kumaraswamy, M.M., Palaneeswaran, E., Rahman, M.M., Ugwu, O.O., \& Ng, S.T. 2006, 'Synergising R\&D initiatives for e-enhancing management support systems', Automation in Construction 15(6), 681-692. http://dx.doi.org/10.1016/j.autcon 2005.10.001

Lee, H.J., Kim, J.W. \& Koh, J., 2009, 'A contingent approach on knowledge portal design for R\&D teams: Relative importance of knowledge portal functionalities' Expert Systems with Applications 36(2), 3662-3670. http://dx.doi.org/10.1016/j. eswa.2008.02.061

Lopes, I.T., 2008, 'Towards an electronic knowledge management culture', The Icfai University Journal of Knowledge Management 6(4), 7-28.

López-Nicolás, C. \& Meroño-Cerdán, A.L., 2011, 'Strategic knowledge management, innovation and performance', International Journal of Information Management 31(6), 502-509. http://dx.doi.org/10.1016/j.ijinfomgt.2011.02.003

Massa, S. \& Testa, S., 2009, 'A knowledge management approach to organizational competitive advantage: Evidence from the food sector', European Management Journal 27(2), 129-141. http://dx.doi.org/10.1016/j.emj.2008.06.005

Mrinalini, N. \& Nath, P., 2008, 'Knowledge management in research and technology organizations in a globalized era', Perspectives on Global Development and Technology 7(1), 37-54. http://dx.doi.org/10.1163/156914907X253206

Ndlela, L.T. \& Du Toit, A.S.A., 2001, 'Establishing a knowledge management programme for competitive advantage in an enterprise', International Journa of Information Management 21(2), 151-165. http://dx.doi.org/10.1016/S02684012(01)00007-X

Potgieter, A., Dube, T.I. \& Rensleigh, C.W., 2012, 'The perception and practice of knowledge management in a research and development facility', The 8th International Conference on Knowledge Management Proceedings, Johannesburg, South Africa, September 4-6, 2012, pp. 198-203.

Robbins, S.P., 2003, Organizational Behaviour, 10th edn., Prentice-Hall, Upper Saddle River.

Sambamurthy, V. \& Subramani, M., 2005, 'Special issue on information technologies and knowledge management', MIS Quarterly 29(2), 193-195.

Sanghani, P., 2008, 'Does organization size matter for starting knowledge management program?', The Icfai University Journal of Knowledge Management 6(1), 7-20.

Schultze, U. \& Leidner, D.E., 2002, 'Studying knowledge management in information systems research: discourses and theoretical assumptions', MIS Quarterly 26(3), 213-242. http://dx.doi.org/10.2307/4132331

Shin, M., 2004, 'A framework for evaluating economics of knowledge management systems', Information and Management 42(1), 179-196. http://dx.doi.org/10.1016/ j.im.2003.06.006

Singh, S.J., 2008, 'Role of leadership in knowledge management: A study', Journal of Knowledge Management 12(4), 3-15. http://dx.doi.org/10.1108/1367327081 0884219

Sultan, N., 2013, 'Knowledge management in the age of cloud computing and Web 2.0: Experiencing the power of disruptive innovations', International Journal of Information Management 33(5), 160-165. http://dx.doi.org/10.1016/j. ijinfomgt.2013.05.010

Teng, B., 2007, 'Managing intellectual property in R\&D alliances', International Journa of Technology Management 38(1), 160-177. http://dx.doi.org/10.1504/IJTM.2007. 012434

Van Beveren, J., 2002, 'A model of knowledge acquisition that refocuses knowledge', Journal of Knowledge Management 6(1), 18-23. http://dx.doi.org/10.1108/ 13673270210417655

Van der Spek, R. \& Kingma, J., 2000, 'Achieving successful knowledge management initiatives', in J. Reeves (ed.), Liberating knowledge, pp. 20-30, Caspian, London. 